\title{
The Modes of Theorizing in Aristotle's Politics
}

Amy L. Shuster, Virginia Polytechnic Institute and State University

ABSTRACT This article addresses the pedagogical value of teaching Aristotle's Politics 4.1 early in an introductory course in political theory that draws texts from the history of political thought. I argue that this chapter provides an interpretive key to understanding arguments made elsewhere in the Politics and can be used to introduce students to the kinds of theorizing that appear in the study of politics more generally. I begin by laying out some common learning obstacles that students experience in introductory political theory courses, using Politics 4.1 to address these issues. I then outline my approach to this text and conclude by reflecting on some of the possibilities and limitations of this method of introducing the nature of political theory to an undergraduate population.

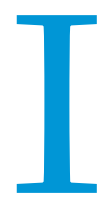

ntroducing students to the study and practice of political theory presents distinct challenges. First, students are often asked to read texts that are difficult not just conceptually, but also at the sentence level. This is especially true in courses that draw readings from the history of political thought. I vividly recall my own experience reading Hobbes during my first semester in college. I remember thinking that I understood each word on the page but not the larger sentence, let alone the larger argument. Lecture and class discussions therefore became a necessary supplement to my reading of the original text. Now, my students report similar experiences of alienation when they read assigned texts. Such difficulty is not unusual or a new observation. Kassiola reports a student who felt "utterly lost" while reading course material $(2007,783)$. When faced with such challenges, many students want class activities to act as a substitute for actually reading the texts. They want lectures to summarize the text or, even better, tell them what they need to memorize for the exam.

Few instructors who teach introductory courses in political theory think that the struggle and alienation involved in reading many of the central texts can or should be removed from the equation. The goal of an introductory course cannot be for most students to understand every (or even one) reading thoroughly and completely by the end of the semester, if only because few professional political theorists can say as much of their own engagement with such texts. Rather, the goal should be to first encourage students to embrace the struggle and then provide them with tools that can help them climb out of the cave on their own. To this end, interpretive tools and frameworks provided in the classroom allow

Amy L. Shuster was an assistant professor of political science at the University of Minnesota Duluth and will be a visiting assistant professor of political science at Virginia Polytechnic Institute and State University. Her research interests link ancient political theory to twentieth century political thought. She has an article on Aristotle's treatment of the Partheniae forthcoming in Polis: The Journal for Ancient Greek Political Thought. She can be reached at Amy.L.Shuster@gmail.com. students to reconstruct the meaning of assigned texts-even the most difficult ones. In this way, class activities supplement students' own reading of the text, rather than serve as a substitute for it.

A second challenge in teaching political theory concerns what we ask our students to do in such a course. Few students educated in the United States have ever been asked to theorize or philosophize about any subject matter before college. Moreover, political theory instructors often ask students to think theoretically about subject matters that students consider devoid of abstraction. Students tend to view politics as a concrete subject, a matter of knowing the facts and using them to their advantage. A philosophy course in ethics may not encounter the same kind of obstacle. Students in moral theory courses can at least understand the question: "What is the right thing to do?" However, students do not view the fundamental questions and problems that propel work in political theory in the same light. For this group, the question "What is politics?" is not recognizable as a problem, nor are many of the other questions that introductory courses in political theory often address. Half the work in teaching political theory seems to involve helping students understand why questions in political theory are genuinely puzzling or open to interpretation. This difficulty is compounded when the assigned texts appear to be of only historical interest.

I use Aristotle's Politics 4.1 as a way to make some headway in overcoming these obstacles to student learning. Principally, this chapter introduces students to the variety of questions that political theory asks in a way that is accessible to a novice learner. The chapter also provides an interpretive framework that students can apply when reading the text on their own, which helps them to solve basic problems of textual interpretation and then raise higher-order questions about the argument of the overall work. In the concluding reflections of this article, I suggest that chapter 4.1 might also help students more deftly navigate the broader study of politics and the kinds of policy considerations that they will face as citizens of a powerful state on the international stage. 
Before delving into the details of how I teach Politics 4.1, it may be helpful to understand the broader context in which this lesson occurs. I adopt a thematic approach to the study of political theory at the introductory level (Kassiola 2007). One classic feature of a thematic approach is the use of only selections drawn from works in the history of political thought with the intent of tracing a consistent issue or related set of issues over the course of the semester. However, I have also used this lesson in an introduction to political science course. In the latter context, students read Politics 4.1 as a stand-alone overview of some of the tasks of political theory. They then use the framework to talk about different ways to approach other issues that arise in the course. This lesson could also be used with novice readers of Aristotle in an upper-division course.

In an introductory course designed around the theme "Democracy and Its Critics," I use one overriding question to direct the discussion of Aristotle: In what ways is Aristotle a critic or supporter of democratic ideas and/or democratic institutions? A casual reading of the Politics finds seemingly conflicting evidence on this point, and students invariably express confusion about how to reconcile this evidence. A total reconciliation may not be possible in the end; Aristotle may contradict himself on some points. However, introducing the Politics through Book 4, Chapter 1 provides students with an important set of tools to grapple with this conflicting evidence. As I will show, Politics 4.1 alerts them to the modes of theorizing that Aristotle deploys in his various discussions, allowing students to discover how some claims do not in fact contradict others.

\section{INTRODUCING THE MODES OF THEORIZING}

In Politics 4.1, Aristotle explains four modes of political theorizing that can be used as interpretive keys to understanding the Politics on its own terms, as well as for interpreting particularly difficult sections of the overall text. Aristotle details these modes after identifying four kinds of advice that a personal trainer might be asked to provide to an athlete or a client. Students find the athletic training analogy to be helpful, as it gives them examples that they can understand before turning to examples that are more difficult and less intuitive. Aristotle specifies the types of advice that are associated with different kinds of training as follows:

1. "What sort is advantageous for what sort of body" (Politics 1288b13-14)

2. "Which is best (for the best is necessarily fitting for the body that is naturally the finest and is most finely equipped)" (Politics 1288b14)

3. "Which is best ... for most bodies" (Politics 1288b14-15)

4. "[What is best] if someone should desire neither the disposition nor the knowledge befitting those connected with competitions" (Politics 1288b16-18)

After pointing out where these distinctions appear in the text, I then ask the students to work briefly in small groups to think about examples of each kind of training and a real-life context in which each might apply. Who is the target audience of each type of advice? What specific advice would be most appropriate for each audience? Once the students have had some time to think in their small groups, I reconvene the full class and we discuss their findings.

Examples for (1) and (3) are typically the easiest for my students to identify. As one student put it, imagine that the trainer is going to recommend a schedule of activities. What are those activities, and how long should they be done? The answer will differ depending on the type of advice that the trainer is called upon to produce. A useful example of training advice for (3) would be the American Heart Association (AHA) recommendation that a healthy amount of exercise for the average adult involves a moderately intense cardiovascular workout for at least 30 minutes a day, five days a week. Students can identify related examples for (1) in the Food and Drug Administration (FDA) recommendations of appropriate caloric intake for people at various activity levels and age ranges and the Food Pyramid, which indicates the best source of these calories in proportion to other food groups. We then discuss the difference between (1) and (3). An individual's particular kind of body is an important consideration with (1) but is not relevant for (3). For instance, training advice for (1) might recommend that pregnant women eat about 300 more calories per day than the average woman, but the level of recommended exercise does not differ for pregnant and average women in the third kind of advice. Therefore, (3) aims to provide general advice, whereas (1) aims to provide slightly more specific advice that is tailored to a subpopulation, rather than the population as a whole.

Students also readily identify Olympic or varsity athletes as the target audience for the type of training that (2) addresses. It is helpful to make the example even more specific, and I prompt my students with the case of Michael Phelps, the 16-time gold-medal Olympic swimmer. We discuss how the recommended workout schedule or health regimes of (1) and (3) would not be appropriate for Michael Phelps. The FDA recommends 2,00o calories per day, but the press famously reported that Michael Phelps eats roughly 12,000 calories per day during swim meets and generally more than 2,00o calories when training for a competition. Similarly, the AHA standard recommendation for a healthy heart would not help Phelps train his heart to work at its peak performance. Thus, someone training for his or her best performance requires different advice than that provided by (1) and (3).

However, the mention of varsity college sports players provides an opportunity to further specify to whom (2) applies, because Aristotle would not necessarily consider this group to be (2)'s target audience. Recall that the type of training concerned in (2) suggests that some people are "naturally the finest." Sports commentators have suggested that Michael Phelps' body is particularly well proportioned for swimming. His upper torso is long and thin, while his legs are relatively short for his height, reducing drag in the water. His arms are longer than usual for his height, which allows a wider and longer reach. His extra-large feet and hyperflexible ankles also make particularly powerful flippers at the end of a stroke. Phelps' body seems naturally inclined to excellence in swimming, naturally fit for the task in a way that training alone cannot reproduce or approximate. ${ }^{1}$ No matter how much or how hard some people train, they will not be able to reproduce these qualities; their body's proportions and maximum ability will be only average. The kind of advice offered in (2) is suitable for people like Phelps specifically, and not for merely devoted and possibly talented athletes who participate in college sports. Of course, the possession of Phelps' body type alone does not mean that he will win another gold medal without training, nor would he have won his first medal without good advice on how to train for competition. Potential does not ensure success. His body still needs the guidance of (2) to recognize its advantages and then train accordingly to experience their full capacity. 
The kind of advice at play in (4) is often the most difficult for students to recognize. For instance, one of my students suggested that (4) might encompass the kind of training that an injured person might receive. However, advice of this kind is really the provenance of (1), for which the sort of body in question is the injured sort of body. I often need to prompt my students with an example for this mode of theorizing. Suppose I ask my personal trainer to suggest an exercise regime that would build my upperbody strength. The trainer performs an assessment of my overall health and notes that my upper-body strength is healthy and normal. I am as strong as an average healthy person should be, which is the goal of (3). I am also as strong as a person of my age and activity level should be, which is the goal of (1). However, I persist in wanting to add exercises to my regular regime that will make my upper body even stronger. This desire does not stem from the (false) impression that my body is naturally fitted for excellence in weight lifting, which might be the reason behind such a request if the kind of advice offered by (2) were relevant to my situation. I have no desire to either enter a weight-lifting competition or engage in any sport that would benefit from such increased strength. I only want to be stronger than I am right now, even while I recognize that I am strong enough for a healthy person with my body type. A related example might concern my friend Mark's request for advice on how to lose 10 pounds before his wedding. This goal is short-term; he does not desire to be healthier in general or to keep off the weight after the wedding. It is also possible that he needs to lose more (or less) than 10 pounds to be in a healthy weight range for his body type. However, Mark does not care about these considerations-he only wants to look good in the wedding pictures and thinks that losing 10 pounds will accomplish this aim. These two cases exemplify what it means to desire "neither the disposition nor the knowledge" of what is best overall or in general. In these examples, neither Mark nor I desire to be the best that we can be, nor do we desire to be generally good overall.

These four types of advice are examples of the range of advice that a good personal trainer should be able to provide according to Aristotle. At this point, the first sentence of the chapter becomes clearer. Aristotle refers to arts and sciences that are "complete" with respect to their subject matter. A "complete" or all-purpose personal trainer can direct any of the four types of training. If a trainer is not capable of advising on one or more of the types, then his or her knowledge of the field is incomplete. Experts, Aristotle argues, aim to develop a comprehensive understanding of their field and are able to tailor their advice or reactions to a situation depending on the nature and needs of the circumstances. Experts can clearly discern when (3) is appropriate and when (2) is warranted. This ability holds for any sort of expert, whether he or she is a doctor, a shipbuilder, a fashion designer, or even a political theorist.

The next step in both my lesson and Aristotle's text is to identify how these four sorts of advice in personal training bear on political theory. Recall that experts in political theory must be able to provide each kind of advice to demonstrate a comprehensive understanding of their field. I again break the students into groups and ask them to comb the second paragraph of the chapter and find citations for each kind of advice. Afterwards, we reconvene and share what they have found. Students can often identify at least three of the four modes, but the mode that is mentioned first in the second paragraph often escapes their attention. The first thing to note is that the types appear in a new order; Aristotle does not maintain a parallel structure when laying out the modes of political theorizing. ${ }^{2}$ The modes are reproduced here in the order in which they appear in the text, but with the number that corresponds to the list of types of advice that a personal trainer might provide:

- (2): "What the best regime is, and what quality it should have to be what one would pray for above all, with external things providing no impediment" (Politics 1288b22-23)

- (1): "Which regime is fitting for which cities" (Politics 1288b24)

- (4): "The regime based on a presupposition-for any given regime should be studied [with a view to determining] both how it might arise initially and in what manner it might be preserved for the longest time once in existence (I am speaking of the case where a city happens neither to be governed by the best regime-and is not equipped even with the things necessary for it-nor to be governed by the regime that is [the best] possible among existing ones, but one that is poorer)" (Politics 1288b27-33)

- (3): "The regime that is most fitting for all cities" (Politics 1288b34-35)

I then compare each moment of the analogy and name each for ease of future reference. ${ }^{3}$ My choice of terminology follows the use of the verb theorein in the original (see Politics 1288b11, 1288b24, 1288b29, 1288b38), which means "to behold" or "to look at." The reconstructed list of modes of theorizing is:

\section{Applied theorizing \\ 2. Pure ideal theorizing \\ 3. Generic theorizing \\ 4. Conditional theorizing}

I further justify the choice of adjectives in this list to clarify the common project that each mode of theorizing concerns. Identifying this project helps students see the connections between the lists.

In the case of the first mode, the general question is what is appropriate ("advantageous" or "fitting") in a particular case ("what sort of body" and "which cities"). I refer to this mode as applied theorizing because the project is to apply a concept (such as appropriateness) to a case study, with attention to its distinctive features. One might then ask from where the understanding of the concept stems. For instance, on what basis can we tell whether something is appropriate? The meaning of the concept comes from the next two sorts of theorizing.

Identifying the common project at stake in pure ideal theorizing is a little more complicated, because one might perceive a tension between the stipulation that this mode pertains to both the "naturally finest" and the best "above all." Given the latter characterization, "pure ideals" might be defined as the unqualified best, but yet the former also suggests a sort of qualification: nature. This tension can be resolved if we understand "above all" to refer to all naturally available options rather than all logically possible ones. In this sense, pure ideal theorizing is not completely divorced from basic facts about humankind, such as the conditions of natality and mortality. Pure ideal theorizing is distinguishable from metaphysical theorizing insofar as the former concerns thinking 
in the context of a human community. Metaphysical theorizing might be interested in thinking about the community of god(s), angels, and other supernatural creatures. Concern for the best regime above all is a consideration of pure ideal theorizing (and not metaphysical theorizing), because according to Aristotle, gods have no need for a political regime.

Another sort of tension appears in examining the third mode, generic theorizing. This mode is first characterized as the best outcome for most X (e.g., bodies or regimes) and then as the most fitting for all $\mathrm{X}$. There is a subtle but important difference between these characterizations. The first seeks to account for the majority of cases, whereas the latter refers to the whole universe of cases. However, I believe that both characterizations represent the same sort of inquiry, since both seek to form generalizations: the former trades on generalized descriptions of the whole group and the latter on a sense of what generally suits each member of the group (although what actually fits a particular member might be different).

Finally, the fourth mode thinks about how to direct a person who desires "neither the disposition nor the knowledge befitting those connected with competitions" (Politics 1288b16-18) or a "regime based on a presupposition" (Politics 1288b27). I refer to this mode as conditional theorizing, because each example asks the theorist to offer advice with a major constraint or assumption limiting the advice. A "presupposition" might include how to make a regime a more stable version of its own form of government without reforming it into a legitimate government.

To check student understanding of these modes, I ask them to identify the mode of theorizing at play in the following passage:

Where the multitude of the poor is preeminent ... there a democracy is what accords with nature-and each kind of democracy according to the preeminence belonging to each sort of people. If, for example, the multitude of farmers predominates, it will be the first sort of democracy; if that of vulgar persons and wage earners, the last sort. (Politics 1296b24-30)

Across two sections of the same course in fall 2010, $53 \%$ of the 66 students who I polled correctly identified this passage as an example of applied theorizing. ${ }^{4}$ This percentage is consistent with results from previous semesters. Thus, generally half of the students are able to apply the modes to a concrete passage. When asked to justify their response, students tend to point out that the passage refers to the demographics of a polity and suggests the best regime for those particular demographics. To continue to build and solidify student understanding of the modes, I then reflect on the relationships among the modes with the goal of helping students distinguish among them in practice. Much of what I say in the remainder of this section relates to student questions that I have fielded in response to the lesson.

Pure ideal theorizing seems to be the clearest concept for students, although its exact nature is often elusive. This mode is recognizable as a fundamentally utopian kind of thinking. Later in the semester, I connect this type of theorizing to Socrates' description of the kallipolis in Plato's Republic and what Rawls refers to as ideal theory. Like the kallipolis, which was only intended to be founded in speech (and which informed Thomas More's coinage of the term "utopia" as a place that is nowhere), I emphasize how the precepts and findings of pure ideal theory are not realizable for any actual human community. Students often then ask why we engage in such theorizing if it has no implication for practical affairs. In fact, pure ideal theorizing does have practical implications. Even if we realize that a pure ideal government is not possible for us, the concept can still serve as a goal to ever more closely approximate or a standard by which to judge our current political institutions and the character of our political activities. At a minimum, this mode fosters humility toward our actual existing political institutions.

Students frequently wonder whether pure ideal theorizing shares important features with generic theorizing, because neither mode is concerned with concrete cases. While these modes do share this feature, other considerations highlight important distinctions between them. Aristotle does not believe that the ideally best city is possible for most cities because they do not have the conditions that one would "pray for" above all. Generic theorizing takes less-than-ideal circumstances-circumstances that are true of the average city or cities in general-into account in determining the best sort of regime. By contrast, the best city according to pure ideal theorizing is not average; it is excellent.

Applied theorizing takes the ideas or precepts developed by pure ideal theory and generic theory and puts them to work on a particular case. In cases that draw upon the precepts of pure ideal theory, applied theory might advise on how to better approximate the ideally best regime by reforming existing institutions. ${ }^{5}$ In cases that draw on the ideas of generic theory, applied theorizing might advise how to reform the city's institutions into generally better or more successful forms of government. Applied theory might also draw on generic theory in providing specific advice about how to found a type of government given the features of a particular city (e.g., its demographics, the possible bases of its economy, geographical context).

Students find it most difficult to distinguish between applied and conditional theorizing. This difficulty is not without just cause: both modes are used in the context of a particular case, which distinguishes them from generic and pure ideal theorizing. Particular cases entail a set of constraints that are peculiar to the case at hand. Both modes of theorizing aim to answer some question or respond to some problem in a case study.

In trying to deepen their understanding of applied and conditional theorizing, students have suggested that conditional theorizing might be a subset of applied theorizing (or vice versa). Students have argued that because constraints are at work in applied theorizing and yet are supposedly the thing that defines conditional theorizing, one mode must be the subset of the other. However, this classification is not what Aristotle intends. I emphasize that the character of the constraints is what distinguishes them. ${ }^{6}$ In particular, artificial constraints also play a role in conditional theorizing. Students then ask how Aristotle distinguishes between natural and artificial constraints. Without digging deeply into Aristotle's metaphysics, it is fair to characterize the distinction as a matter of what is reasonably possible given available resources (natural constraints) versus what is actually possible given some unnecessary restriction on what is reasonably possible (artificial constraints). To recall an earlier discussion, for instance, Aristotle would identify the fact that body proportion matters for swimming as a natural constraint. Similarly, birth and death are natural constraints in the human condition. However, my friend Mark's desire to lose only enough weight to look good in his wedding pictures is an artificial constraint on his overall wellness and possible excellence. Similarly, a tyrant's desire to make his or her regime more stable without making it an overall 
Table 1

Student Responses to Interpretive Questions before and after Lesson, by Percentage

\begin{tabular}{lccc} 
& $\begin{array}{c}\text { CORRECT } \\
\text { ANSWER }\end{array}$ & $\begin{array}{c}\text { BEFORE } \\
\text { (\%) }\end{array}$ & $\begin{array}{c}\text { AFTER } \\
\text { (\%) }\end{array}$ \\
\hline Is Politics 4.11 describing the best regime for the best city imaginable? & No & 52 & 78 \\
\hline Is Politics 4.11 describing the best regime for the typical city? & Yes & 69 & 85 \\
\hline Are Politics 7.1 and 7.13 describing the best regime for the best city imaginable? & Yes & 39 & 60 \\
\hline Are Politics 7.1 and 7.13 describing the best regime for the typical city? & No & 51 & 67 \\
\hline
\end{tabular}

the class period, and $16 \%$ indicated that their confidence was "much greater." ${ }^{8}$ Students' level of confidence is important, because while confidence does not ensure accurate interpretation, it does keep students engaged and feeling able to go back to the text to learn more on their own. Students will only become better interpreters when they practice more, and increased confidence makes it better regime or the best possible regime for the community acts as an artificial constraint on a political advisor. While natural constraints figure into the thinking that occurs in applied theorizing, conditional theorizing considers constraints that are both natural and artificial. Therefore, following Kraut, the circumstances at work in the latter are less flexible (2002, 430).

After drawing a distinction between natural and artificial constraints, one final point of clarification can be made about how natural constraints figure into pure ideal theorizing (although not in the same way that they figure into applied theorizing). Humans are by definition not supernatural creatures like gods; they can be killed, and all eventually die. These facts amount to a set of natural constraints that cannot be avoided, even in pure ideal theorizing. However, pure ideal theorizing is different from applied theorizing in terms of the range or kind of natural constraints that it takes into account. Pure ideal theorizing aims to think in light of "the very best" natural constraints, the ones we "pray" for above all. For instance, pure ideal theorizing aims to describe Michael Phelps' body when characterizing the best swimmer's body. Applied theorizing thinks in terms of actually available resources, not naturally possible ones; available resources are likely (far) less than ideally best resources. By distinguishing between these kinds of theorizing, Aristotle is signaling that experts must be able to think about the best possible regime given the available resources, even if the ideally best resources are not immediately at hand or reasonably possible. Thus, compared to pure ideal theorizing, applied theorizing takes into account a wider range of natural constraints, which have a less-than-ideal character.

I have found that the ability of students to interpret arguments in Aristotle's Politics improves dramatically over the course of a single class. To illustrate, consider student responses to a series of questions that I asked before and after the lesson in the two sections of the same course in fall 2010 (see table 1). ${ }^{7}$ In advance of class, I ask the students to read Politics 4.11, 7.1, and 7.13. Before the lesson, $69 \%$ correctly identified that Politics 4.11 describes the best regime for the typical city, and only $39 \%$ identified that Politics 7.1 and 7.13 describe the best regime for the ideally best city. After the lesson, 85\% correctly identified Politics 4.11, representing a $16 \%$ improvement in student understanding, and $60 \%$ correctly identified Politics 7.1 and 7.13 , representing a $20 \%$ improvement. After administering these questions, I review the results with the students and ask them to indicate what textual evidence led them toward the answer that they gave, even if they did not change their response. This discussion helps struggling students see the modes in practice. After this discussion, $57 \%$ of the students indicated that their confidence in interpreting Aristotle was "a little greater" than it was at the beginning of more likely that they will try again.

There is clearly room for improvement in student learning. While only $60 \%$ of students thought that Politics 7.1 and 7.13 were about the ideally best regime by the end of the lesson, in the next question, $67 \%$ correctly rejected the claim that these selections were about the best regime for a typical city. During the debriefing, students explained that they did not mark the shift in the mode of theorizing until the second question and wished that they could change their answer. However, in general, students were less certain of their assessment of Politics 7.1 and 7.13 than they were of their assessment of Politics 4.11. This disparity suggests that the modes need to be reinforced over several class periods. Several weeks later, $70 \%$ recognized the definition of happiness as "the complete practice and actualization of virtue" as an example of pure ideal theorizing. Regardless, students reported that the modes helped them to see that Aristotle was not contradicting himself in recommending a form of democracy for one city and a form of aristocracy for the ideally best city. The next section explores the details of these chapters in more depth to illustrate how the modes of theorizing can help students learn how to resolve some interpretive problems.

\section{APPLYING THE MODES OF THEORIZING TO COMMON INTERPRETIVE PROBLEMS}

I have so far argued that Politics 4.1 is a good way to introduce students to the various ways of thinking theoretically about politics and the different kinds of questions on which a political theorist might provide counsel. I also believe that the four modes of theorizing outlined in this chapter serve as an interpretive key to resolving apparent inconsistencies or puzzles in Aristotle exegesis. This section will discuss a few concrete examples to illustrate how instructors might use the modes of theorizing to help students understand some of Aristotle's arguments.

An acute first-time reader of Aristotle is apt to notice the apparent inconsistency of claims like the following:

a. Aristotle refers to the form of aristocracy that distributes offices and honors on the basis of virtue alone (Politics 1294a9) as the true-to-type or genuine and first or best (alethinen kai proten) form of aristocracy (Politics 1294a25).

b. In 4.11, Aristotle seems to argue that the middle-class regimethat is, a regime ruled by people of "middling and sufficient property" (Politics 1295b30)-is the best form of governance for most cities.

c. In the midst of the same chapter, Aristotle also claims that "the political partnership that depends on the middling sort is the best" (Politics 1295b35). He claims further that "the city wishes 
... to be made up of equal and similar persons to the extent possible, and this is most particularly the case with the middling elements" (Politics 1295b25-27).

d. Aristotle identifies the farmer as the best sort of common person at Politics $1318 \mathrm{~b} 10$ and indicates that a democracy composed primarily of farmers is the best sort of democracy.

e. Politics 7.13 indicates that to know what type of regime is characteristic of the ideal state, one must first understand that the purpose of this state is to secure and promote happiness among its citizens. Aristotle has an idiosyncratic definition of happiness as "the complete practice and actualization of virtue" (Politics 1332a9-11). Therefore, if a type of regime has been identified as a result of its ability to secure happiness, and if happiness is tied to virtue, then the ideal state is a form of aristocracy-the form specified in (a).

When asked to identify the best sort of government given the previous evidence, novice interpreters of Aristotle regularly believe that (a) and (e) conflict with (c) and (d), and that some tension exists between (c) and (d). However, upon closer inspection, it becomes clear that Aristotle is engaging in different modes of theorizing that resolve any apparent contradictions in his thought.

Consider the context in which (b) and (c) appear. Without the lens of the modes of theorizing, novice readers do not notice the opening lines of the chapter, which mention that the focus of analysis is "most cities" and not the ideally best city (Politics 1295a25). A little further on, Aristotle again mentions that the intent of the chapter is to figure out the "way of life which it is possible for most to participate in, and a regime that most cities can share" (Politics 1295a3o). With the assistance of the list of modes, students are able to recognize that generic theorizing is at play in this chapter. Therefore, when they encounter a claim like (c), they remember the theoretical context in which such a statement occurs and do not confuse it with another kind of theorizing. ${ }^{9}$ The description in (c) of a city of "equal and similar persons to the extent possible" (emphasis added) suggests that there are ways of conceptualizing equality that fall short of complete equality; however, pure ideal theorizing is concerned with complete equality. We can then ask: On what basis are the citizens equal? The passage in (b) suggests that equality is measured with respect to property. By contrast, when employing pure ideal theorizing, citizens are equal with respect to virtue. (Thus, pure ideal theorizing informs the concepts of generic theorizing as well, but a broader set of constraints apply in the latter case.) In the end, we can ask: Why is the statement in (b) and (c) an example of generic theorizing? According to Aristotle, all cities comprise three main parts: the poor, the rich, and the middle class. Given both this generic description of cities and the assumption that one of these classes must rule alone, then it is best that the middle class assume power, because this form of rule results in a relatively stable government. ${ }^{10}$

If Aristotle prefers a middle-class regime for most cities, then under what circumstances does he think that democracy is best? In other words, in what mode of theorizing is he engaging during the discussion of the best sort of democracy in Politics 6.4 that is mentioned in (d)? Given their contemporary sensibilities, students commonly think that the middle-class regime and the farmer democracy are the same sort of regime. However, Aristotle indicates that farmers do not have much property (Politics 1318b13), which disqualifies them from membership in the middle class, given the definition of this class that is laid out in (b). To solve this problem, students need to first identify the kind of theorizing that is occurring throughout Book 6 and then appreciate how Chapter 4 contributes to this enterprise. The end of 6.1 and the beginning of 6.2 both identify a focus on a presupposition (hypothesis). In 4.8, Aristotle mentions how some regimes have a defining principle, or basic presupposition, about what the government should preserve. This terminology calls to mind conditional theorizing. The implication is that the ideally best regime does not rule by presupposition, nor should one measure its success by a presupposition, as this approach adds an artificial constraint. The presupposition of democracy is freedom (Politics 1294a11, 1317a40). In 6.4, Aristotle argues that when the citizens of a state are largely farmers, they form the best sort of democracy, because this type of state promotes freedom more than other kinds of democracy.

We are then left with (a) and (e) in need of explanation: What mode of theorizing is at play in these analyses? Students can deploy the same strategy used in the previous case to answer this question-that is, they can examine what the book as a whole is doing. Predictably, Aristotle announces his focus in the first chapter of Book 7: he aims to determine "the best regime" and "the most choiceworthy way of life" (Politics 1323a14-15). However, is he referring to the best regime based on a presupposition or the best regime in general? The answer is neither. The beginning of 7.13 clarifies matters by placing its focus on the city that is "blessed" (makarios; Politics 1331b25). This terminology calls to mind pure ideal theorizing. As Michael Phelps is blessed with a uniquely good body for swimming, so the ideally best city is blessed with the special character of its institutions and culture. This chapter also clarifies why freedom or stability are not the ends of the ideally best city. The beginning of the chapter suggests three ways in which someone can fail to live well: when the wrong end is posited, when bad means to the correct end are deployed, or when the wrong end is pursued by way of bad means (Politics 1331b30-33). According to this chapter, the democratic presupposition of freedom and the middle-class commitment to equality and stability are instances of the first sort of failure, because they fail to appreciate how happiness is the end of the city. Freedom, equality, and stability are necessary but not sufficient features of the ideally best regime. While a democrat might think that freedom is definitive of happiness, Aristotle believes that this conflation misunderstands happiness, which he defines as "the actualization and complete practice of virtue" (Politics 1332a9). He indicates that this definition of happiness is "not on the basis of a presupposition (hypothesis) but absolutely (haplos)" (Politics 1332a10). ${ }^{11}$

This section has sought to illustrate how I use these different modes of theorizing in my introductory course, and in particular, how these modes can shed light on Aristotle's stance toward democracy. The vocabulary used to describe the case is a good barometer of the type of theorizing; in the previous examples, the word "most" often indicates generic theorizing (although not in the context of "the most choiceworthy way of life"-a common distractor for students); "presupposition" relates to conditional theorizing, and "blessed" pertains to pure ideal theorizing. A focus on vocabulary provides students with greater command over the text at the level of the sentence and thus makes confusing passages feel less alienating. In subsequent classes, I ask students to look for textual evidence when reading to keep track of the sort of theorizing in which Aristotle is engaging when he makes a particular claim. This assignment gives the students a specific and 
consistent question to answer as they are reading and empowers them to connect the dots on their own.

\section{CONCLUDING REFLECTIONS}

A principal reason why the different modes of theorizing are important is that Aristotle seems to have been the first to recognize that the same constitution might not be appropriate for all circumstances. ${ }^{12}$ Thus, identifying the distinctions among the modes of theorizing allows students to discover that the ideally best regime-the product of pure ideal theorizing-is not necessarily the right kind of regime to be established when founding or reforming a city. ${ }^{13}$ Instead, students can discover how Aristotle believes that one should take into account the city's natural and, where necessary, artificial constraints when offering political counsel or leading legislative reform. In more concrete terms: understanding Aristotle's modes of theorizing can help students to recognize that American-style democracy is not necessarily the best possible regime for every state and might not even be the best regime imaginable. When viewing other countries around the world, Aristotle's mode of applied theorizing reminds us that political institutions need to be sensitive to political circumstances and history. Transitional politics is premised on the need to be clear about which mode is most appropriate. Although justice according to pure ideal theorizing may demand that corrupt politicians be held accountable for their actions, conditional theorizing can highlight the practical tradeoffs between reconciliation and justice.

Standard scholarly commentary typically treats this list of Aristotelian modes as an introduction to political science broadly, not political theory in particular. ${ }^{14}$ The idea that political theory is only a field within the discipline of political science is absent from both Aristotle's work and ancient thinking about politics more generally. A fuller appreciation of how Aristotle conceives the relationship between political theory and other types of theoretical and practical inquiry would relate this list to the account of intellectual virtues presented in Book 6 of the Nicomachean Ethics. ${ }^{15}$ However, that project is beyond the scope of this article.

The list of Aristotelian modes functions particularly well as a vivid illustration of the range of modes of theorizing on which an introductory course in political theory draws, especially a course that works with texts from the history of political thought. This exercise helps students by introducing them to the idea that political theory or theoretical thinking about politics is a multifaceted enterprise. Moreover, this exercise is valuable because it uses a text that is also the object of students' analysis and allows them to deduce the kinds of thinking in which they will engage over the course of the semester. In other words, political theorists can teach methodology without sacrificing content. Aristotle's Politics can thus serve a double purpose as an early work in political theory that forwards arguments about the course theme and as a methodological introduction to the field of political theory more generally. A methodological introduction is especially useful to students in such a class because they are apt to have no preconceived notions about the content of the course or the kinds of thinking with which they will engage. Some might argue that students should simply "do" political theory before being introduced to methodological considerations. But I question whether it is preferable to go on a hike knowing the way or knowing that you will be lost for most of the way. ${ }^{16}$ I think that it is easier to focus on and appreciate the beauty of the path when you have a clear map.
In the end, these four modes of theorizing do not exhaust the range of thinking that students employ in political theory courses. Nor do these modes fully represent the kind of work produced by scholars who identify or are identified as political theorists. Different modes of theorizing will surely need to be added to this list, and existing kinds may need to be further broken down to accurately characterize the various methodologies and preoccupations of contemporary political theory. However, the range of thinking in political theory is better represented by these modes than alternative ways of conceptualizing the field. For instance, the ubiquitous Rawlsian distinction between ideal and non-ideal theory elides the diversity of questions that scholars ask in nonideal theory, whereas the list from Politics 4.1 includes at least three different kinds of questions that one might ask under the aegis of non-ideal conditions. Moreover, the Aristotelian list calls attention to the different sorts of considerations that one should keep in mind when engaging with each type of non-ideal theory. Another common distinction between descriptive or explanatory theories and prescriptive or normative theories seems to obscure the way in which these modes may be and often are connected in contemporary scholarship. ${ }^{17}$ By contrast, this typology from Aristotle's Politics provides a way for students to understand possible connections among the different modes of theorizing about politics and thus begin to see how theory is "meaning-constitutive" (Warren 1989). ${ }^{18}$ Short of assigning an entire book or collection of articles on the matter, examining these modes of theorizing in Aristotle's Politics provides a useful and engaging starting point for an introductory undergraduate course. ${ }^{19}$.

\section{NOTES}

I am grateful for feedback from an anonymous reviewer from PS, Eve Browning, Barbara Buckinx, Tristram McPherson, and faculty and students in political science and philosophy at the University of Minnesota Duluth.

1. Hadhazy (2008) reports that the claims about Phelps' physiological features that are advanced in other press sources might not be sufficient to explain his success, and that Phelps' body might not be dramatically different from the bodies of other top Olympic swimmers. While Hadhazy agrees that all Olympic swimmers' bodies are naturally better fitted to the task than most bodies, he may misrepresent the argument about the role of Phelps' body in particular: it is not dramatic differences but marginal ones that give him a competitive advantage. Regardless, the utility of this example depends more on the possibility that it models than on its strict accuracy.

2. Whether these lists are in fact parallel is a matter of some scholarly debate. I follow Simpson $(1998,285)$ and Miller $(1995,184 \mathrm{n} 87)$ in reading them as compatible, although these scholars' appreciation of what the two lists share is slightly different from my own. Simpson, for instance, takes this list as a matter of "the best and the best attainable" (1998, 285-86), whereas I believe that these modes of theorizing encompass a broader set of concerns.

3. One could also add the discussion at Politics 1289b12-25 to this list.

4. Of this $66,32 \%$ indicated generic theorizing, $12 \%$ conditional theorizing, and $3 \%$ pure ideal theorizing.

5. Barker $(1959,444)$ claims that the connection between moral and political theory is lost in Politics 4.1. However, my line of argument suggests a way to see how this chapter maintains the connection: pure ideal theorizing involves moral theorizing, and applied theorizing makes use of pure ideal theorizing.

6. See also Kraut $(2002,431)$ for a different but compatible way of thinking about this distinction.

7. Students received no particular credit for their responses to these questions and thus had no incentive to get the answers right. I collected responses anonymously through personal response devices ("clickers") and a Turning Point presentation.

8. $22 \%$ indicated that their confidence was "unchanged," $1 \%$ that it was "a little less," and $3 \%$ that it was "much less." Over half of the students who reported that their confidence was "unchanged" at the end of the lesson had reported a high or very high level of confidence before the lesson. These results suggest that the lesson most improves the confidence of those students who are most in need of such improvement. 
9. A student once punctuated this assessment by pointing to the very end of this chapter: "What the best regime is, then, and for what reasons, is evident from these things ... provided one is not judging with a view to a presupposition. I say 'with a view to a presupposition' because while one sort of regime is more choiceworthy, there is often nothing to prevent another regime being more advantageous for certain [cities]" (Politics 1296b2-3 and 1296b9-12).

10. The chapter details a set of reasons for why cities in general will be more stable when ruled by the middle class.

11. This argument is difficult to substantiate from within the Politics; to defend this claim fully, one needs to draw on Aristotle's ethical discourses. However, students can use the form of theorizing to better understand the nature of the argument that Aristotle is making.

12. Newman (1973, xxxi) most prominently made this point.

13. Alternatively, as Lord $(1987,143)$ points out, "incremental change" in the direction of the ideal regime is often more preferable than mere proselytizing about how things should be, if only because it is a more successful strategy in the end.

14. See, for instance, Simpson (1998, 284-85), Robinson (1962, 67) and Barker (1959, 444). I follow Kraut (2002) in interpreting the modes more narrowly as questions for political theory. In an even more narrow context, Schütrumpf (1989) interprets Politics 4.1 as an agenda for constitutional theory.

15. I am optimistic that these lists are fully compatible. Regardless, in the contex of an introductory course, it is preferable to turn to the Politics for an account of Aristotle's method rather than the Nicomachean Ethics, if only for the sake of simplicity and contextual consistency.

16. Thanks to Eve Browning for suggesting this analogy.

17. This line of criticism is not new, of course. See, for instance, Hacker (1961, $1-6)$. In the more specific context of Aristotle exegesis, Salkever $(1981,494)$ distinguishes between the interpretive moment of understanding a polity's nomoi and the critical or evaluative moment of assessing nomoi in light of the good or justice.

18. These examples are illustrative. There is a variety of ways for distinguishing modes of theorizing. For instance, Grant $(2002,578)$ contrasts experimental and interpretive theories and Thiele (2003) contrasts scientific theories and hermeneutics.

19. Leopold and Stears (2008) edited a volume that attempts to represent the range of modes of political theorizing in contemporary scholarship. The "further reading" list included at the end of the volume is a useful resource. See also the edited volume by Frank and Tambornino (2000) and the special thirtieth anniversary issue of Political Theory (2002), which asked a variety of leading scholars to answer the question "What is political theory?" Rehfeld $(2010,475)$ also aims to provide a comprehensive typology of the various forms of political theory in the contemporary American academy. However, an introductory undergraduate course rarely has the time to engage in such metatheoretical discussions.

\section{REFEREN C E S}

Aristotle. 1984. The Politics. Trans. Carnes Lord. Chicago: University of Chicago Press.
Barker, Ernest. 1959. The Political Thought of Plato and Aristotle. New York: Russell and Russell.

Frank, Jason A., and John Tambornino, eds. 200o. The Vocations of Political Theory. Minneapolis: University of Minnesota Press.

Grant, Ruth. 2002. "Political Theory, Political Science, and Politics." Political Theory 30 (4): 577-95.

Hacker, Andrew. 1961. Political Theory: Philosophy, Ideology, Science. New York: Macmillan.

Hadhazy, Adam. 2008. "What Makes Michael Phelps So Good? Do Phelps's Body Shape and Flexibility Give the Eight-Gold-Medal Winner a Physical Edge in Swimming?" ScientificAmerican.com. http://www.scientificamerican.com/ article.cfm?id= what-makes-michael-phelps-so-good.

Kassiola, Joel. 2007. "Effective Teaching and Learning in Introductory Political Theory: It All Starts with Challenging and Engaging Assigned Readings." PS: Political Science and Politics $40(4): 783-87$.

Kraut, Richard. 2002. Aristotle: Political Philosophy. Oxford: Oxford University Press.

Leopold, David, and Marc Stears, eds. 20o8. Political Theory: Methods and Approaches. Oxford: Oxford University Press.

Lord, Carnes. 1987. "Aristotle." In History of Political Philosophy, 3rd ed., ed. Leo Strauss and Joseph Cropsey, 118-54. Chicago: University of Chicago Press.

Miller, Fred D. 1995. Nature, Justice and Rights in Aristotle's Politics. Oxford: Clarendon Press.

Newman, W. L. 1973. The Politics of Aristotle, vol. 3. New York: Arno.

Political Theory. 2002. "Political Theory, What Is Political Theory? Special Issue: Thirtieth Anniversary." Political Theory 30 (4): 471-619.

Rehfeld, Andrew. 2010. "Offensive Political Theory." Perspectives on Politics 8 (2): 465-86.

Robinson, Richard, trans. 1962. Aristotle Politics Books III and IV. Oxford: Clarendon.

Salkever, Stephen G. 1981. "Aristotle's Social Science.” Political Theory 9 (4): 479-508.

Schütrumpf, Eckart. 1989. "Platonic Methodology in the Program of Aristotle's Political Philosophy: Politics IV.1." Transactions of the American Philological Association 119: 209-18.

Simpson, Peter L. Phillips. 1998. A Philosophical Commentary on the Politics of Aristotle. Chapel Hill: University of North Carolina Press.

Thiele, Leslie Paul. 2003. Thinking Politics: Perspectives in Ancient, Modern and Postmodern Political Theory. 2nd ed. New York: Chatham House.

Warren, Mark E. 1989. "What is Political Theory/Philosophy?" PS: Political Science and Politics 22 (3): 606-12.

\section{Appendix: Basic Lesson Plan (50 minutes)}

1. Introduce the general question: What is political theory? (1-2 minutes)

2. Turn to Politics 4.1 and identify the four kinds of advice that a personal trainer might provide. (8-10 minutes)

3. Break students into small groups. Ask them to generate examples of each kind of advice from their personal experience or a hypothetical situation. (5 minutes)

4. Regroup and share findings. Deepen understanding of each type through discussion of examples. (10 minutes)

5. Break students into small groups again. Ask them to identify the four kinds of advice as they appear in the second paragraph, the discussion of political theory. (5 minutes)

6. Regroup and share findings. Discuss reordering of list. (5 minutes)

7. Draw parallels between the lists to generate the more general mode of theorizing operating in each kind. Compare and relate the types to each other. (10 minutes)

8. Set up next reading assignment. Ask students to identify the mode of theorizing in which Aristotle is engaging for each of the assigned chapters over the course of the unit. (2 minutes)

In future class sessions: Use this list as a way to resolve tensions about the best regime, extend into other assigned texts to build list. 